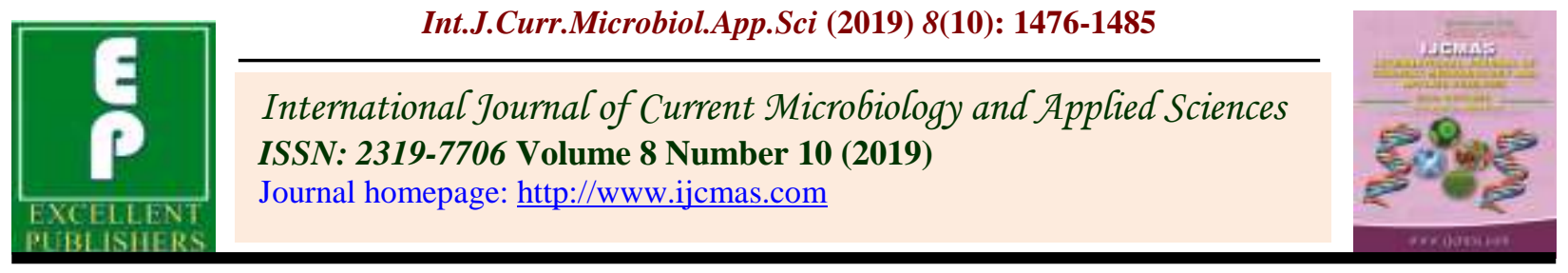

Review Article

https://doi.org/10.20546/ijcmas.2019.810.173

\title{
A Review on the Performance of Different Routing Protocols in WSN- A Comparative Survey
}

\author{
Tushar Kumar Pandey ${ }^{1 *}$, Ishita Singh ${ }^{2}$ and Manoj Kumar ${ }^{3}$ \\ ${ }^{1}$ Department of Computer, ARIS Cell, RPCAU, Pusa, India \\ ${ }^{2}$ Department of Computer, VC Cell, RPCAU, Pusa, India \\ ${ }^{3}$ Department of Computer, DoEE, RPCAU, Pusa, India
}

*Corresponding author

\begin{tabular}{|l|}
\hline Key w o r d s \\
WSN, LEACH, \\
Postural-based, \\
Temperature-based, \\
Cross-layer, \\
Cluster-based \\
\hline Article Info \\
\hline $\begin{array}{l}\text { Accepted: } \\
\text { 12 September } 2019 \\
\text { Available Online: } \\
\text { 10 October } 2019\end{array}$ \\
\hline
\end{tabular}

A B S T R A C T
Topology issues should receive more and more consideration in Wireless Sensor Networks (WSN). While the supplied underlying network topology typically optimizes WSN applications, another inclination is observed to optimize WSN employing topology control. In the current ten years, wireless sensor network technology has speedy development. After a concise prologue of the wireless sensor network, some main protocols of WSN are provided. Then the comparison is made between the various protocols with advantages and disadvantages. Besides, the sensor node, sink node, the user node consist of the three elements of sensor networks. Sensor node remains the basis of the whole network, they are liable for the study of data, processing data, store data and transmit data. Lifetime expansion is one of the most significant analysis problems in the field of wireless sensor networks due to the critical resource deficiencies of the sensor nodes. By summarizing the previous performance of different routing protocols in WSN, we also point out possible research directions for future work.

\section{Introduction}

WSN is a growing technology for low-cost, unused monitoring of a broad expanse of environments. Modern advancements in micro-electrical mechanical systems (MEMS) and low power and deeply integrated digital electronics head to the expansion of micro sensors. These sensors estimate the ambient circumstances associated to the environment and convert them into an electrical signal. The processed output of such signal shows about the characteristics of the objects discovered or events occurring in the surroundings of the sensor. The sensor transfers such collected data to the sink directly or to the data 
collection centre called as gateway. Sensor nodes are limited to energy supply and bandwidth, and these limitations connecting with a typical deployment of a large number of nodes have modelled many difficulties to the study and control of sensor networks. So these difficulties require energy-awareness at all layers of the networking protocol stack.

The problems related to the physical and link layers are common for all types of sensor applications, and therefore research in these areas focus on system levels power information including dynamic voltage scaling, radio communication hardware, low duty cycle issues, system partitioning and energy-aware MAC protocols. Several routing techniques, including data aggregation, clustering, many node role assignment and data-centric methods, are applied in a WSN environment to reduce energy consumption. According to the network structure in WSN, routing protocols can be categorized as flat, hierarchical or location-based. All nodes perform the identical role in flat networks.

Hierarchical protocols direct to cluster the nodes so that cluster heads can work some aggregation and reduction of data to save energy. In location-based routing, the memory and bandwidth utilisation is reduced such that the only the one hop neighbour's knowledge is required to route the data to the destination and this decreases the number of control overheads. In location-based protocols the location information of the node is utilised to send the data to the sought destination rather than the whole network.

A fuzzy logic model is proposed for cluster head election. The proposed model follows five descriptors to define the possibility for each node to become a Cluster $\operatorname{Head}(\mathrm{CH})$. These descriptors include residual energy, location suitability, density, compacting, and distance from the base station. This fuzzy logic model is employed to propose the Fuzzy Logic-based Energy-Efficient Clustering for WSN based on minimum separation Distance enforcement between CHs (FL-EEC/D). The Gini index is adopted to estimate the clustering algorithms' energy efficiency based on their ability to weigh the distribution of energy through WSN sensor nodes (1).

The accessible policies and solutions for IoT Network Management and devices are surveyed in (2). Amongst all the available technologies, an assessment was conducted employing features including heterogeneity, scalability, supported technologies, and security. Based on this assessment, the most hopeful technologies were adopted for a comprehensive performance evaluation study through simulation and deployment mechanisms in real environments.

(3) Introduces WBAN and concentrates on the study of the routing protocol, analyse, and examine the benefits and drawbacks of several routing protocols.

(4) Provided a precise study on the QoS mechanisms that have been used by routing protocols and also highlights the execution issues of all mechanisms. The survey shows a comparative study of computational intelligence based QoS-aware routing protocols with their powers and weaknesses. Finally, this survey considers several possible areas for future research in the field of QoS provisioning at network layer.

(5) Represents the theories of wireless charging of sensors nodes with energyefficient manner in WSN. The concepts of wireless charging node in WSN are explored providing details of literature review and comparing well-known works. It supports new scholar to decide on current methods and more investigate about energy transfer to the sensor nodes in wireless sensor network. 
In (6) requirement of research of underwater sensor networks has been described along with reviewing various literatures in which various research articles are analysed. Among these research studies, some difficulties are still prevailing for further research. Most common difficulties include workload characterization, resource management, lifetime evaluation, losses, no communication, real-time monitoring, expense, deployment, spatial correlation, power, low battery power, long and variable propagation delays, multipath, low" bandwidth.

(7) Showed the implementation of cluster head selection in WSN using FCR method which was the extension of conventional firefly algorithm. Since the primary contribution of the paper is on selecting the cluster head for facilitating the routing process, the comparative study was limited by demonstrating the performance of the proposed cluster head over the other cluster heads. Once the proposed cluster heads are selected for routing, the state-of-the-art routing protocols can be adopted for data transfer.

In (8)a thorough and up to date review of these coverage protocols are presented. It is found that the performance of these protocols is mainly restricted by difficulties associated to discovering a more practical coverage model for the sensor nodes in the networks. More precisely, most of the proposed coverage protocols sleep on less realistic theories such including location awareness and regularity of the signal intensities within a sensing and/or a transmission range. Moreover, most of these protocols utilise an idealized energy consumption model.

To win some of the constraints and problems of some of the current cluster-based routing protocol in (9), stable, energy-efficient and secure, adaptive and dynamic routing protocol for static nodes in WSNs (ADRPS) is introduced. It is based on the popular LEACH protocol, but instead of using the signal strength or the smallest distance between pair of nodes, it practices the acknowledgment.

(10) Offers a precise survey on Computational Intelligence (CI) techniques-based routing protocols in WSN. Furthermore, a comparable analysis of investigated protocols with their strengths and shortcomings is also incorporated in the survey. This paper considers several possible routes which guide the researcher to create effective routing protocols by combining WSN with CI techniques.

In (11) the power amplification model and threshold energy are chosen as metrics. The comparison with the existing models shows the metrics are efficient in improving the existence of the network. For future improvement, more metrices are needed to be recognised to build a better network model.

In(12) a unique optimization scheme is introduced with the goal of improving the clustering techniques called as MSoC or multi-scale optimized clustering, where a novel clustering technique is presented with an attention of single and multi-level clustering approximation method. The technique also offers an idea of RF Transceiver that can resolve the energy problems in data aggregation for wide range WSN. The outcome gained from the study shows better performance with regard to energy conservation on larger number of simulation rounds till date in comparison to existing techniques.

In (13) the authors expanded in various practical WBAN scenarios employing MAC protocol and tested in more generic Time Division Multiple access (TDMA) approach to bypass packet collision which drives to higher 
packet loss rate. It is examined in numerous generic topologies, comparing to the model's performance to the highly esteemed and several remarkable methodologies in the literature. Simulation results reveal enhanced performance of the proposed protocols in association to the selected existing ones in terms of the chosen performance metrics.

In (14) comparative analysis of reactive protocols (LEACH and LEACH-C), single mobile node protocol (NDCM), and multiple mobile node-based hybrid protocol (HADMMN) is performed. Application of multiple mobile nodes significantly enhances the performance of the network.

In (15) the various energy-efficient routing protocols for clustering of sensor nodes in wireless sensor network, its merits, demerits and applications are discussed. The thought behind the protocols is summarised along with the benefits and fields that could be improvised.

\section{Hierarchical routing protocols}

In hierarchical routing algorithms, a lot of nodes are partitioned into groups. Each cluster has a node, which is assigned as the group head. Along these lines, each node is either a group head or one remote jump far from the cluster head as appeared in Figure 1. A node that isn't a group head, however neighbouring more than one group head, is alluded to as a portal. Parcels between group heads are directed through gateways. Finally, nodes that are neither cluster heads nor entryways are alluded to as normal nodes. The subnet containing the group heads and doors is alluded to as the spine organize. Here, each cluster head keeps up data about different nodes in its group, and every now and then, this data is traded between group heads over the system. Along these lines, the cluster heads assemble organize topology data. A node that has a bundle to send to another node can acquire steering data from its cluster head. It isn't fundamental for a parcel to be directed through the spine, as information parcels might be directed along other progressively proficient courses in the system.

Hierarchical clustering is additionally named as topology aware directing as the nodes utilize the information of the system topology to course messages. There are a few different ways of actualizing this methodology. The main probability is that every node decides the ideal way to each node in the framework and stores this data. Each time a flood of packets must be sent from a source to a goal, an association is set up between two end-focuses and all the packets pursue this way. Be that as it may, with an evolving topology, nodes will have to refresh their steering data and restore ways that were broken during correspondence. On the off chance that the system topology does not change all the time, it is likely that the way foundation expenses are brought about once initially furthermore; every resulting bundle is directed without extra overhead. The second probability is connectionless steering, where a course is resolved on the fly for each packet as it moves starting with one node then onto the next. This technique will expect nodes to store less data about system topology. Notwithstanding, each packets brings about the directing overhead.

\section{Cluster based routing protocols}

In cluster based routing scheme the MANET is divided into several overlapping or disjoint groups called clusters as depicted in Figure 2. A development node called as cluster head is chosen from each gathering for keep up directing related assignments. Clustering in MANETs lessens the overhead from part nodes and improves framework execution too. Between cluster, courses are set up through group related data kept up by cluster head (Table 1). 
Table.1 This section will comprise of the comparative analysis of the different routing protocols techniques in a tabular form. The comparison can be made with respect to the objectives, the approach being used, protocol, results obtained and limitations

\begin{tabular}{|c|c|c|c|c|c|}
\hline $\begin{array}{l}\text { Ref } \\
\text { No }\end{array}$ & Objectives & $\begin{array}{l}\text { Approach } \\
\text { used }\end{array}$ & Protocol & Results & limitations \\
\hline 1 & $\begin{array}{l}\text { To enhance the } \\
\text { energy efficiency } \\
\text { with regards to } \\
\text { network lifetime } \\
\text { and energy } \\
\text { consumption } \\
\text { providing balance } \\
\text { to between sensor } \\
\text { nodes for different } \\
\text { network sizes and } \\
\text { topologies }\end{array}$ & $\begin{array}{l}\text { The FL- } \\
\text { EEC/D } \\
\text { technique }\end{array}$ & LEACH & $\begin{array}{c}\text { An average } \\
\text { enhancement is } \\
\text { observed in terms } \\
\text { of first node dead } \\
\text { and half nodes } \\
\text { dead }\end{array}$ & $\begin{array}{c}\text { An average } \\
\text { upgradation was } \\
\text { observed for first node } \\
\text { dead and half node } \\
\text { dead. }\end{array}$ \\
\hline 3 & $\begin{array}{l}\text { To analyse the } \\
\text { energy efficient } \\
\text { routing protocols } \\
\text { for WBANs in the } \\
\text { field of healthcare } \\
\text { systems. }\end{array}$ & $\begin{array}{l}\text { Open source } \\
\text { and throttling }\end{array}$ & $\begin{array}{c}\text { Postural-based, } \\
\text { temperature- } \\
\text { based, cross- } \\
\text { layer, cluster- } \\
\text { based, and } \\
\text { Qos-based } \\
\text { routing }\end{array}$ & $\begin{array}{l}\text { Different routing } \\
\text { protocols have } \\
\text { different results } \\
\text { based on the } \\
\text { application }\end{array}$ & $\begin{array}{l}\text { The limitations of } \\
\text { different protocol are } \\
\text { different. No agility is } \\
\text { there. }\end{array}$ \\
\hline 4 & $\begin{array}{c}\text { To review various } \\
\text { potential directions } \\
\text { for future research } \\
\text { in the field of QoS } \\
\text { provisioning at } \\
\text { network layer }\end{array}$ & $\begin{array}{c}\text { Service } \\
\text { orientation, } \\
\text { clustering, } \\
\text { multiple } \\
\text { routing } \\
\text { metrics, } \\
\text { mobile sink, } \\
\text { multiple sinks, } \\
\text { multipath } \\
\text { routing }\end{array}$ & $\begin{array}{l}\text { QoS routing } \\
\text { protocol }\end{array}$ & $\begin{array}{l}\text { Supports } \\
\text { heterogeneous } \\
\text { traffic load } \\
\text { Effectively shares } \\
\text { the available } \\
\text { constrained } \\
\text { resources among } \\
\text { the different } \\
\text { traffic classes }\end{array}$ & $\begin{array}{l}\text { Needs dynamic priority } \\
\text { assignment. Not } \\
\text { adaptable to dynamic } \\
\text { network conditions }\end{array}$ \\
\hline 5 & $\begin{array}{l}\text { To enhance the } \\
\text { energy of every } \\
\text { sensor node after } \\
\text { the deployment in } \\
\text { the network. }\end{array}$ & $\begin{array}{l}\text { Two mobile } \\
\text { vehicles for } \\
\text { charging the } \\
\text { wireless } \\
\text { sensors } \\
\text { wirelessly }\end{array}$ & $\begin{array}{l}\text { Conventional } \\
\text { protocols, } \\
\text { LEACH, } \\
\text { DEEC }<\text { SEP }\end{array}$ & $\begin{array}{l}\text { There is no issue } \\
\text { with the stability } \\
\text { in the network }\end{array}$ & $\begin{array}{l}\text { Limitations of } \\
\text { continuous energy } \\
\text { supply. }\end{array}$ \\
\hline 6 & $\begin{array}{c}\text { To study of } \\
\text { underwater sensor } \\
\text { networks }\end{array}$ & $\begin{array}{l}\text { Underwater } \\
\text { sensor } \\
\text { networks } \\
\text { (UWSNs) }\end{array}$ & MRP & $\begin{array}{l}\text { MRP showed } \\
\text { improvement in } \\
\text { terms of end-to- } \\
\text { end delay, energy } \\
\text { consumption, and } \\
\text { delivery ratio }\end{array}$ & $\begin{array}{l}\text { Low bandwidth, High } \\
\text { propagation delay and } \\
\text { lesser transmission } \\
\text { power. }\end{array}$ \\
\hline
\end{tabular}




\begin{tabular}{|c|c|c|c|c|c|}
\hline 7 & $\begin{array}{l}\text { To choose optimal } \\
\text { cluster head to } \\
\text { achieve energy } \\
\text { efficient and delay } \\
\text { less routing in } \\
\text { WSN }\end{array}$ & FCR & $\begin{array}{l}\text { state-of-the-art } \\
\text { routing } \\
\text { protocols }\end{array}$ & $\begin{array}{l}\text { It has conserved } \\
\text { the distance } \\
\text { between the nodes } \\
\text { by minimizing it }\end{array}$ & $\begin{array}{l}\text { Security constraints } \\
\text { and other practical } \\
\text { constraints are not fully } \\
\text { developed. }\end{array}$ \\
\hline 8 & $\begin{array}{l}\text { To review the } \\
\text { coverage problem } \\
\text { and identify the } \\
\text { challenges faced in } \\
\text { providing complete } \\
\text { coverage model for } \\
\text { the sensor nodes in } \\
\text { the networks. }\end{array}$ & $\begin{array}{l}\text { Sensor } \\
\text { deployment } \\
\text { model }\end{array}$ & $\begin{array}{l}\text { Coverage } \\
\text { Protocols }\end{array}$ & $\begin{array}{l}\text { Network } \\
\text { connectivity is } \\
\text { found to be an } \\
\text { extremely crucial } \\
\text { factor in designing } \\
\text { future solutions. }\end{array}$ & $\begin{array}{l}\text { A discrete radio model } \\
\text { is needed to achieve } \\
\text { more accurate and } \\
\text { realistic calculation. }\end{array}$ \\
\hline 9 & $\begin{array}{l}\text { To enhance the } \\
\text { Performance of } \\
\text { Wireless Sensor } \\
\text { Network }\end{array}$ & ADRPS & $\begin{array}{c}\text { Cluster-Based } \\
\text { Adaptive and } \\
\text { Dynamic } \\
\text { Routing } \\
\text { Protocol }\end{array}$ & $\begin{array}{l}\text { It works well in } \\
\text { situations, } \\
\text { involving large } \\
\text { number of sensor } \\
\text { nodes, large } \\
\text { number of round } \\
\text { and finding } \\
\text { alternative paths } \\
\text { dynamically, } \\
\text { adapting any } \\
\text { critical condition } \\
\text { like path break or } \\
\text { path failure in } \\
\text { comparison }\end{array}$ & $\begin{array}{l}\text { The proposed approach } \\
\text { is not much explored. }\end{array}$ \\
\hline 10 & $\begin{array}{l}\text { To address various } \\
\text { routing issues in } \\
\text { WSN }\end{array}$ & $\begin{array}{c}\text { QoS } \\
\text { mechanism }\end{array}$ & $\begin{array}{l}\text { Computational } \\
\text { intelligence- } \\
\text { based energy } \\
\text { efficient } \\
\text { routing } \\
\text { protocols }\end{array}$ & & $\begin{array}{l}\text { Cross level mechanism } \\
\text { is not well developed. } \\
\text { It never involves } \\
\text { complicated } \\
\text { interactions among } \\
\text { MAC and routing } \\
\text { layers. }\end{array}$ \\
\hline 11 & $\begin{array}{c}\text { To enhance the } \\
\text { lifetime of the } \\
\text { network }\end{array}$ & $\begin{array}{l}\text { Power } \\
\text { amplification } \\
\text { model }\end{array}$ & $\begin{array}{l}\text { Energy- } \\
\text { Efficient } \\
\text { LEACH } \\
\text { Protocol }\end{array}$ & $\begin{array}{l}\text { It enhances the } \\
\text { lifetime of the } \\
\text { network }\end{array}$ & $\begin{array}{l}\text { Accurate recognizing } \\
\text { some more metrics is } \\
\text { still not fully developed } \\
\text { to build a better } \\
\text { network model. }\end{array}$ \\
\hline 12 & $\begin{array}{l}\text { To introduce a } \\
\text { mechanism of } \\
\text { clustering where } \\
\text { multiple non-linear } \\
\text { attributes are used } \\
\text { to select better }\end{array}$ & $\begin{array}{l}\text { Multi-scale } \\
\text { Optimized } \\
\text { Clustering } \\
\text { The proposed } \\
\text { study } \\
\text { considers the }\end{array}$ & $\begin{array}{l}\text { LEACH } \\
\text { protocol }\end{array}$ & $\begin{array}{l}\text { It shows better } \\
\quad \text { energy } \\
\text { conservation over } \\
\text { increasing rounds } \\
\text { of simulation }\end{array}$ & $\begin{array}{l}\text { Results depend on } \\
\text { more number of } \\
\text { simulations. }\end{array}$ \\
\hline
\end{tabular}




\begin{tabular}{|c|c|c|c|c|c|}
\hline & $\begin{array}{c}\text { form of cluster } \\
\text { head. }\end{array}$ & $\begin{array}{c}\text { research } \\
\text { methodology }\end{array}$ & & & \\
\hline 13 & $\begin{array}{l}\text { To assess the } \\
\text { performance and } \\
\text { efficiency of the } \\
\text { proposed protocol }\end{array}$ & WBAN & $\begin{array}{c}\text { Energy } \\
\text { Efficient } \\
\text { TDMA based } \\
\text { MAC Protocol }\end{array}$ & $\begin{array}{c}\text { It provides } \\
\text { improved network } \\
\text { lifetime and } \\
\text { minimized packet } \\
\text { loss. }\end{array}$ & $\begin{array}{l}\text { Energy is less due to } \\
\text { clock synchronization }\end{array}$ \\
\hline 14 & $\begin{array}{l}\text { To improve the } \\
\text { network } \\
\text { performance }\end{array}$ & $\begin{array}{c}\text { Multiple } \\
\text { mobile nodes }\end{array}$ & $\begin{array}{l}\text { Energy- } \\
\text { Efficient } \\
\text { Routing } \\
\text { Protocols }\end{array}$ & $\begin{array}{l}\text { Multiple mobile } \\
\text { nodes provide } \\
\text { better performance } \\
\text { as compared to } \\
\text { single mobile data } \\
\text { collector. }\end{array}$ & $\begin{array}{l}\text { It is difficult to identify } \\
\text { the optimal number of } \\
\text { mobile nodes, link } \\
\text { brakeage, speed at } \\
\text { which mobile nodes } \\
\text { must move, and } \\
\text { trajectory for mobile } \\
\text { nodes }\end{array}$ \\
\hline 15 & $\begin{array}{l}\text { To achieve energy } \\
\text { efficiency and } \\
\text { better network } \\
\text { lifetime }\end{array}$ & Sensor nodes & $\begin{array}{c}\text { Energy- } \\
\text { Efficient and } \\
\text { Lifetime- } \\
\text { Enhanced } \\
\text { Clustering } \\
\text { Algorithm- } \\
\text { Based Routing } \\
\text { Protocols }\end{array}$ & $\begin{array}{l}\text { It shows better } \\
\text { energy efficiency, } \\
\text { reliability, load } \\
\text { balancing and } \\
\text { network lifetime }\end{array}$ & $\begin{array}{l}\text { Sensor nodes have } \\
\text { limited battery life. }\end{array}$ \\
\hline
\end{tabular}

Fig.1 Clustering example

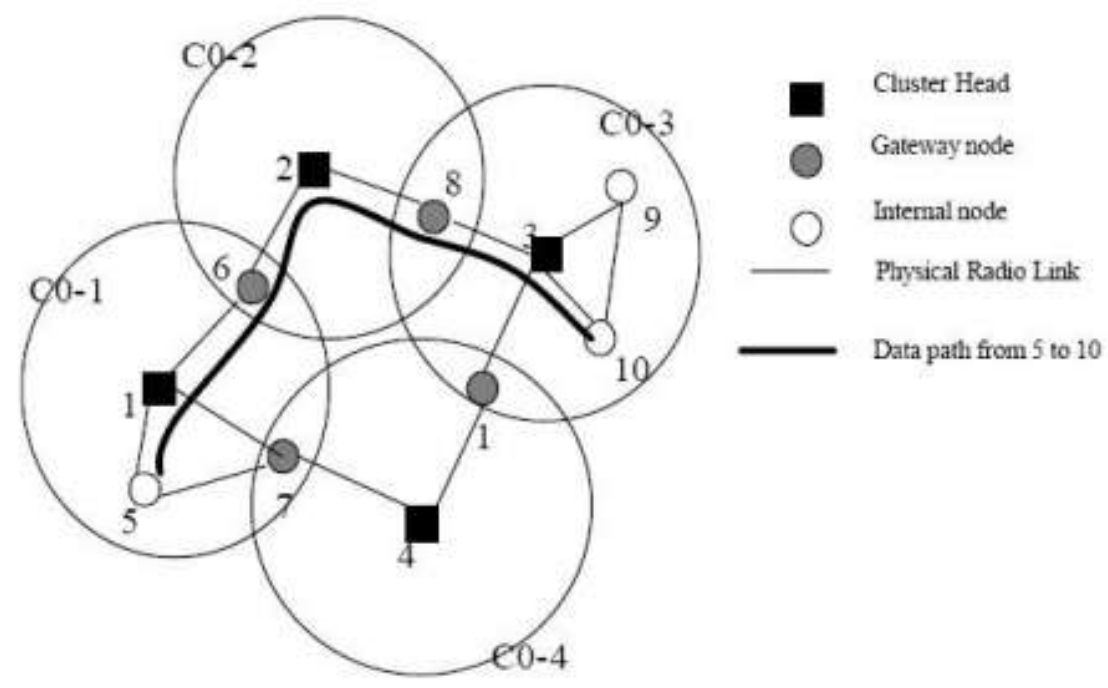


Fig.2 Cluster Illustration

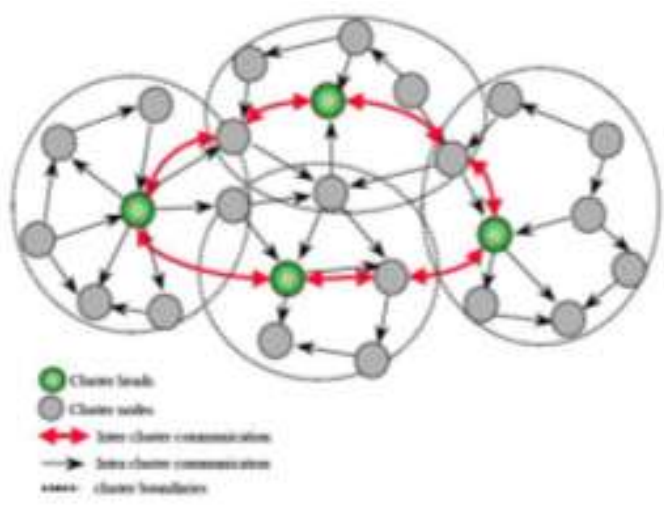

Cluster based routing has below mentioned characteristics:

Totally circulated procedure.

It diminishes traffic circulation while the dynamic course revelation process.

Local fix can be given to broken connections without the necessity of course rediscovery process. To bringing down the entrance of overhead while topology change, groups are utilized in such conventions. Because of the dynamic system structure, the support of group data ends up troublesome before they are utilized. Then again, channel task is the central assignment done by these clusters. Cluster based steering convention (CBRP) suggests the clustering calculation however dissimilar to other directing conventions, the utilization of groups in the steering procedure is the key thought of CBRP.

\section{QOS metrics and challenges}

Quality of service (QoS) relates to all technologies that maintain data traffic to lessen packet loss, latency and jitter on the network. QoS checks and controls network resources by setting preferences for particular types of data on the network. QoS is normally defined as a set of service conditions that require to be satisfied by the network while moving a packet stream from a source to its destination. The service conditions of end-user applications govern the network requirements.

The network is required to ensure a set of measurable pre-specified service associates to the users in terms of end-to-end performance, such as delay, bandwidth, probability of packet loss, etc. Power consumption is an added QoS attribute which is more particular to MANETs. In the literature, the research on QoS support in MANETs traverses over all the layers in the network. QoS routing is complicated in Mobile Ad hoc Network. First, Overheads of QoS is too high for insufficient bandwidth because mobile hosts should possess the mechanisms to collect and modernise link state information.

Second, because of the dynamic nature of MANETs, maintaining the precise link state information is very challenging. Third, the plain meaning that the demanded QoS should be ensured once a feasible path is discovered is no longer true.

The reserved resource may not be guaranteed because of the mobility- caused path breakage or power depletion of the mobile host. QoS 
routing protocols explore routes with adequate QoS requirements. QoS routing protocol meets end-to-end QoS requirements, such as delay, bandwidth demand or multi metric constraints. The QoS metrics could be concave or addictive.

In this survey paper, we have reviewed the major routing protocols in WSN including LEACH, Postural-based, temperature-based, cross-layer, cluster-based, and QoS-based routing, QoS routing protocol Conventional protocols, LEACH, DEEC SEP, MRP, stateof-the-art routing protocols, Coverage Protocols, Cluster-Based Adaptive and Dynamic Routing Protocol, Computational intelligence-based energy efficient routing protocols, Energy-Efficient LEACH Protocol, LEACH protocol, Energy efficient TDMA based MAC Protocol, Energy-Efficient Routing Protocols, Energy-Efficient and Lifetime-Enhanced Clustering AlgorithmBased Routing Protocols.

In short, the wireless sensor network is a widespread expansion prospect of one of the high technology. It connects sensor technology, embedded computing technology, new network and wireless communication technology.

\section{References}

Hamzah, A., Shurman, M., Al-Jarrah, O., and Taqieddin, E. (2019). Energy-Efficient Fuzzy-Logic-Based Clustering Technique for Hierarchical Routing Protocols in Wireless Sensor Networks. Sensors, 19(3), 561.

Silva, J. D. C., Rodrigues, J. J., Al-Muhtadi, J., Rabêlo, R. A., and Furtado, V. (2019). Management Platforms and Protocols for Internet of Things: A Survey. Sensors, 19(3), 676.

Qu, Yating, Guoqiang Zheng, Huahong Ma, Xintong Wang, Baofeng Ji, and
Honghai Wu. "A Survey of Routing Protocols in WBAN for Healthcare Applications. "Sensors 19, no. 7 (2019): 1638.

Kaur, Tarunpreet, and Dilip Kumar. "A survey on QoS mechanisms in WSN for computational intelligence-based routing protocols. "Wireless Networks (2019): 1-22.

Prakash, S., \&Saroj, V. (2019). A Review of Wireless Charging Nodes in Wireless Sensor Networks.Data Science and Big Data Analytics (pp. 177-188). Springer, Singapore.

Khan, G., Dwivedi, R. K., and Gola, K. K. (2019). Comparative Analysis of Routing Algorithms for Underwater Sensor Network. In Pervasive Computing: A Networking Perspective and Future Directions (pp. 31-46). Springer, Singapore.

Sarkar, A., \&Murugan, T. S. (2019). Cluster head selection for energy efficient and delay-less routing in wireless sensor network. Wireless Networks, 25(1), 303-320.

Elhabyan, Riham, Wei Shi, and Marc StHilaire. "Coverage Protocols for Wireless Sensor Networks: Review and Future Directions. "arXiv preprint arXiv:1901.00511 (2019).

Jain, S. R., and Thakur, N. V. (2019). ClusterBased Adaptive and Dynamic Routing Protocol to Enhance the Performance of Wireless Sensor Network.In Third International Congress on Information and Communication Technology (pp. 351-359).Springer, Singapore.

Kaur, T., and Kumar, D. (2019). Computational intelligence-based energy efficient routing protocols with QoS assurance for wireless sensor networks: a survey. International Journal of Wireless and Mobile Computing, 16(2), 172-193.

Krishnakumar, A., and Anuratha, V. (2019). 
Energy-Efficient LEACH Protocol with Multipower Amplification for Wireless Sensor Networks. In Pervasive Computing: A Networking Perspective and Future Directions (pp. 103-110). Springer, Singapore.

Jyothi, A. P., and Usha, S. (2019). MSoC: Multi-scale Optimized Clustering for Energy Preservation in Wireless Sensor Network. Wireless Personal Communications, 1-20.

Marinkovic, Stevan, Christian Spagnol, and Emanuel Popovici. "Energy-efficient TDMA-based MAC protocol for wireless body area networks."2009 Third International Conference on
Sensor Technologies and Applications. IEEE, 2009.

Mohan, B. A., and Sarojadevi, H. (2019). Energy-Efficient Routing Protocols for WSNs: A Comparative Analysis. In Smart Intelligent Computing and Applications (pp. 259-265). Springer, Singapore.

Banerjee, I., and Madhumathy, P. (2019). Study on Energy-Efficient and Lifetime-Enhanced Clustering Algorithm-Based Routing Protocols in Wireless Sensor Network. Emerging Research in Computing, Information, Communication and Applications (pp. 87-98). Springer, Singapore.

\section{How to cite this article:}

Tushar Kumar Pandey, Ishita Singh and Manoj Kumar. 2019. A Review on the Performance of Different Routing Protocols in WSN- A Comparative Survey. Int.J.Curr.Microbiol.App.Sci. 8(10): 1476-1485. doi: https://doi.org/10.20546/ijcmas.2019.810.173 